\title{
The Effect of Six Weeks of High-Intensity Interval Training With Zinc Supplementation on Some Humoral Immunity Markers in Female Futsal Players
}

\author{
${ }^{1}$ Malihe Saeedy, ${ }^{1}$ Nahid Bijeh ${ }^{*},{ }^{1}$ Mahtab Moazzami \\ ${ }^{1}$ Exercise Physiology Department, Faculty of Physical Education and Sport Sciences, Ferdowsi University of \\ Mashhad, Mashhad, Iran.
}

\begin{abstract}
Background. It seems strenuous trainings have a suppressing effect on the immune function and athletes performing such trainings are probably prone to infectious diseases due to weakened immune system. Objectives. The aim of this study was to examine the effect of six weeks of high-intensity interval training (HIIT) with and without zinc $\mathrm{n}$ serum immusupplementation onoglobulin concentrations in female futsal players. Mthods. Thirty-two female futsal players were randomly divided into 4 groups like placebo, Zinc, HIIT+Placebo and Zinc+HIIT. All athletes had to attend futsal-specific training 3 sessions per week. Zinc and Placebo groups took $30 \mathrm{mg}$ day-1 of zinc gluconate or dextrose, respectively, and HIIT groups performed 6-10 repetitions of a 30-second running at $100 \%$ of VO2peak with 4-minutes rest between the efforts during six weeks. Results. IgM levels decreased significantly in placebo group (from 136.25 \pm 34.44 to $119 \pm 33.53, \mathrm{p}=0.003$ ) and Zinc group (from 143.25 \pm 52.96 to $123.62 \pm 50.33$, $\mathrm{p}=0.005)$. 6 weeks of HIIT did not change the levels of IgA, IgM and IgG significantly ( $>>0.05)$. HIIT along with Zinc augmented IgA value (from $179.75 \pm 54.49$ to $211.12 \pm 89.22$, p=0.049), significantly; It also increased IgM and IgG levels which were not significant $(\mathrm{p}>0.05)$. Conclusion. It can be concluded that 6 weeks of HIIT had no suppressing effect on the immune system in female futsal players; even HIIT along with Zinc supplementation improved the immune system via increasing IgA value.
\end{abstract}

KEY WORDS: Interval Training, Zinc Supplement, Immunoglobulin A, Immunoglobulin M, Immunoglobulin G.

\section{INTRODUCTION}

It is known that immune response to physical activity depends on the intensity of activity and athletes undergoing heavy training are probably more prone to infectious diseases resulting from a weakened immune system (1). Owen et al. (2016) showed that high intensity soccer training might cause a significant decrease in s-IgA values post-exercise as compared to low intensity training (2). Lee et al. (2015) indicated that there was reduced trend of $\operatorname{IgA}$ in male adults after 12 weeks of Judo training or resistance combined with Judo training or interval training combined with Judo training (3). One of these heavy trainings isOne of these heavy trainings is High-intensity Interval Training (HIIT) being performed by athletes in

*. Corresponding Author:

Nahid Bijeh

E-mail: bijeh@ferdowsi.um.ac.ir 
order to improve their exercise performance. Controversial results have been observed in different investigations on the impact of HIIT on the immune system. Majority of the studies have shown that HIIT suppressed the immune system; while others have reported that these trainings did not affect the immune system $(1,4-7)$. In a few cases, it has been reported that HIIT improved the immune function (8).

The immune system, which protects the body against the pathogens, consists of innate immunity and adaptive immunity. If an infectious agent overcomes or passes the innate immunity, the adaptive immunity, including $\mathrm{T}$ and B lymphocytes, deals with it. Immunoglobulins, which are released through B lymphocytes, play an important role in the extracellular defense $(9,10)$. Among the five classes of human immunoglobulin, IgA, IgM, and $\mathrm{IgG}$ are more important in the resistance against infectious agents. They exist in the serum and tissue fluids and protect the body against different bacteria, viruses, and parasites (11-13). Immunoglobulins do not destroy invaders carrying the antigen directly. They contribute to the destruction of those invaders through neutralization, agglutination, and opsonization processes $(9,10)$.

The role of various supplements has been investigated in several studies to reduce the suppressing effect of strenuous training on the immune function $(14,15)$. In some studies, it has been reported that supplementation modulated the immune function after intense training(14, 16), whereas in some cases it did not cause significant changes in the immune system (17, 18).

Research on the effects of supplementation on immunoglobulins during heavy training is either very limited or contradictory. Crooks et al. (2006) observed that bovine colostrum consumption for 12 weeks increased the salivary IgA in endurance runners, while 10 weeks of bovine colostrum supplementation caused no difference in the concentration of immunoglobulins in elite male and female swimmers $(17,19)$.

One of the impressive supplements for the immune system is zinc. Zinc is vital for normal development and function of the innate immunemediated cells, neutrophils, and NK. It also effects the lymphocytes $\mathrm{T}$ maturity and is an essential part of enzymes involved in the immune system. Hence, zinc has a decisive role in immune function (20). In addition, zinc as an antioxidant and anti-inflammatory agent (21), is involved in cellular respiration and the reproduction of DNA, maintains the integrity of cell membranes, and acts against free radicals (22). The lucrative effects of zinc supplementation on various diseases, such as acute diarrhea in infants, cold, etc., have been reported in different studies (20, 23, 24). However, data from this study on the combined effect of zinc supplementation and heavy training on the immune function are quite limited. Singh et al. (1994) has indicated that six days of zinc supplementation before the aerobic exhaustive training improved the immune function of male runners (25).

It seems strenuous trainings have a negative effect on immune function, and athletes performing such trainings are probably prone to infectious diseases due to a weakened immune system. To reduce this suppressing effect of heavy training on the immune system, the role of various supplements has been investigated in several studies. On one hand, various supplements have shown contradictory effects on the immune system, while on the other; the effects of zinc supplementation on the immune system during high-intensity interval or heavy training have hardly been investigated. Also, data gathered for this study seems insufficient. Due to improvement in both anaerobic and aerobic power, and low training volume and training time, HIIT has attracted the attention of many coaches and athletes. However, this type of training may lead to suppression of the immunity system, and hence the researcher has put forward the question that whether six weeks of HIIT suppresses the immune function or creates an adaptation in the immune system. Also, the use of antioxidant supplements in order to enhance the antioxidant system and immune function has become popular nowadays. Another question is whether an antioxidant supplement, such as zinc, can affect the immune system or not? Therefore, the aim of this study is to examine the effects of six weeks of HIIT with zinc supplementation on some humoral immunity markers in female futsal players. 


\section{MATERIALS AND METHODS}

This is semi-experimental, double-blind trial, applied research containing pre-test and post-test phases with four groups. This study was approved by the ethics committee of the Ferdowsi University of Mashhad (code 61681).

Participants. The study population consisted of female futsal players from the city of Mashhad. A total of 50 female futsal players met the inclusion criteria and were willing to cooperate. Thirty-two out of the 50 female futsal players (mean age: $23.31 \pm 3.89$ years, height: $162.25 \pm 5.85 \mathrm{~cm}$, weight: $55.21 \pm 6.29 \mathrm{~kg}$, BMI: $20.93 \pm 1.74 \mathrm{~kg} / \mathrm{m}^{2}$ ) who had at least 4 years of sports background voluntarily participated in this study. For two months prior to the intervention, all the athletes had regularly participated in futsal team trainings (only 2 sessions per week). Inclusion criteria included: age range (18-28 years) and BMI $\left(18-23 \mathrm{~kg} / \mathrm{m}^{2}\right)$. All the subjects were healthy and had not been used zinc or any other supplements for at least two months before the start of the study.

Study Design. First of all, the nature of the study was orally announced in all female futsal clubs around Mashhad city by researcher; next, personal and contact information of futsal players who were interested in the cooperation was recorded, and then 32 individuals were purposefully selected from 50 volunteers. In a meeting, the objectives, the research process and researcher's expectations from the athletes were described in detail; afterwards, a consent form, a demographic questionnaire, medical questionnaire and Kaiser Physical Activity questionnaire were completed by the participants. Then, the athletes' height, weight and BMI were measured. Two days before intervention, blood samples were collected (pretest phase). The participants were randomly divided into 4 groups including placebo $(n=8)$, Zinc $(\mathrm{n}=8)$, HIIT+Placebo $(\mathrm{n}=8)$ and Zinc+HIIT $(n=8)$, and were influenced by the interventions for 6 weeks. Lastly, two days after the last training session, the blood samples were collected again (post-test phase). The athletes' height, weight and BMI were also measured again one day after blood sampling.

It should be mentioned that the athletes were supposed to attend futsal league competitions two months later; in this way, the beginning of our project and their preparation phase, were at the same time. Even more, the participants would have been eliminated from our survey, if they had been absent from the training more than 2 sessions.

Measurements. The athletes' height and weight were measured using the Seca 220 Stadiometer (Germany) with a sensitivity of 5 $\mathrm{mm}$ and $100 \mathrm{~g}$, respectively. Their BMI was evaluated with a body composition analyzer (Inbody 720, South Korea).

It should be noted that the athletes were intimated about the exact time of blood sampling for both the instances, and were advised to avoid intense physical activity 24 hours prior to it. Also, blood samples were taken at least three hours after eating their last meal so that their bladder, stomach, and intestines were not full. In addition, the participants were asked to record their diet for three days before the primary blood sampling in a recall questionnaire and follow the same diet before the secondary blood sampling. It should also be noted that none of the participants were menstruating during blood sampling (primary and secondary).

Blood samples $(7 \mathrm{cc})$ were taken from the antecubital vein by a qualified person in a sport salon at the Ferdowsi University of Mashhad, before futsal training, between 17:00 and 18:00. The blood samples were centrifuged for 5 minutes at $3000 \mathrm{rpm}$ to separate the serum. Then, they were frozen at $-20^{\circ} \mathrm{C}$ (26). Finally, $\operatorname{IgA}, \operatorname{IgM}$, and $\operatorname{IgG}$ were measured in the serum samples with the help of nephelometry method. Based on the instructions of Kit (UK Company, Binding Site), the serum samples were diluted with a related buffer in the ratio of 1:11 (40 $\mu \mathrm{l}$ of serum with $400 \mu \mathrm{l}$ of buffer). Then, $40 \mu \mathrm{l}$ of specific antiserum was added to the sample and mixed well. Using the nephelometry device (United States) and a binding site kit (United Kingdom), the light absorbance was immediately recorded. Finally, the concentration of these factors was measured with the standard curve (27). Also, the serum zinc levels were measured by the atomic absorption spectrophotometry method.

Training Protocol. All athletes had to participate in futsal -specific training 3 sessions per week with the start of the study. In addition to futsal training in every session, HIIT+Placebo 
and HIIT+Zinc groups had to perform HIIT protocol as below (Fig. 1), after a warm-up and before futsal-specific training. High-intensity interval training contained 6-10 repetitions of a 30 -second running at $100 \%$ of $\mathrm{VO}_{2 \text { peak }}$ with a 4 minutes rest between the efforts (28).

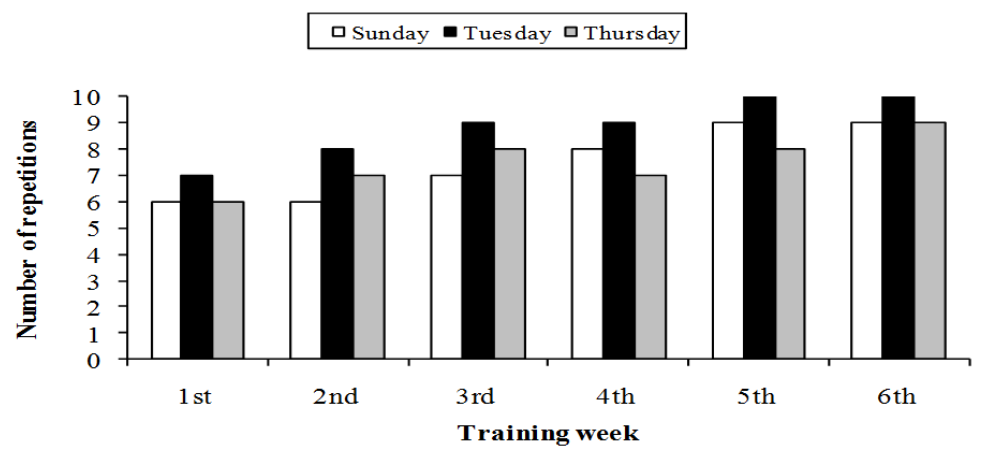

Figure 1. HIIT protocol

Supplementation Protocol. The athletes in Zinc and Zinc+HIIT groups took Zinc $(30 \mathrm{mg}$ zinc gluconate (29) distributed by Nature Made Nutritional Products made in U.S.A) and the athletes in placebo and placebo+HIIT group took dextrose (30), 2 hours after dinner every day. Moreover, the participants had no history of using supplements at least two months prior to the project; they were also asked to avoid using any other supplement during the study period.

Statistical Analysis. Lastly, this data was analyzed using SPSS (version 16). The mean and SD of the data were calculated using descriptive statistics. Then, repeated measure analysis of variance was used to compare the differences within a group, as well as between two groups. An assumption of compound symmetry covariance matrix was examined by the M-Box test. The statistical significance was considered at $\mathrm{p}<0.05$. The values were stated as mean \pm SD.

\section{RESULTS}

Table 1 showed that the variance was homogeneous for each of three dependent variables in all four groups; so we are allowed to use repeated measure analysis of variance to compare the variables means in pre and post test phases in all groups.

Table 1. Results of M Box test to evaluate the compound symmetry of covariance matrix

\begin{tabular}{cccc}
\hline Variable & Box's M & F & P Value \\
\hline $\operatorname{IgG}$ & 11.305 & 1.093 & 0.364 \\
\hline $\operatorname{IgM}$ & 23.839 & 2.305 & 0.214 \\
\hline $\operatorname{Ig} \mathrm{A}$ & 15.999 & 1.547 & 0.125 \\
\hline
\end{tabular}

After 6 weeks, IgM decreased (from $136.25 \pm 34.44$ to $119 \pm 33.53 \mathrm{mg} / \mathrm{dl}, \mathrm{p}=0.003)$ in placebo group, significantly, whilst $\operatorname{IgA}$ and $\mathrm{IgG}$ augmented insignificantly. In Zinc group, we witness a significant decrease in IgM (from $143.25 \pm 52.96$ to $123.62 \pm 50.33 \mathrm{mg} / \mathrm{dl}, \mathrm{p}=0.005)$; increased $\operatorname{IgA}$ and decreased $\operatorname{IgG}$ were not significant in this group. More, 6 weeks of HIIT elevated $\operatorname{IgA}$ and $\operatorname{IgM}$ and reduced $\operatorname{IgG}$, insignificantly. Eventually, 6 weeks of HIIT along with zinc supplementation made a significant increase in IgA (from 179.75 \pm 54.49 to $211.12 \pm 89.22 \mathrm{mg} / \mathrm{dl}, \mathrm{p}=0.049$ ); we also observed an increase in $\operatorname{IgM}$ and $\operatorname{IgG}$ in this group which were not significant (Table 2, Fig. 2).

Table 2 indicated that the means of within groups in $\operatorname{IgM}$ variable in placebo $(\mathrm{p}=0.003)$ and Zinc $(\mathrm{p}=0.005)$ group as well as in $\operatorname{IgA}$ variable in HIIT+Zinc group $(\mathrm{p}=0.049)$ changed 
significantly. A significant interactive change was only observed in IgM value ( $\mathrm{p}=0.014)$.

Table 2. Differences within groups and between groups of IgA, IgM and IgG concentrations before and after the interventions

\begin{tabular}{|c|c|c|c|c|c|c|}
\hline \multirow[b]{2}{*}{ variables } & \multirow[b]{2}{*}{ group } & \multicolumn{2}{|c|}{ stage } & \multicolumn{3}{|c|}{ changes } \\
\hline & & $\begin{array}{l}\text { Pre-test } \\
(\mathrm{M} \pm \mathrm{SD})\end{array}$ & $\begin{array}{c}\text { Post-test } \\
(\mathbf{M} \pm \text { SD })\end{array}$ & $\begin{array}{l}\text { within } \\
\text { group } \\
\text { (p value) }\end{array}$ & $\begin{array}{l}\text { interactive } \\
\text { (p value) }\end{array}$ & $\begin{array}{l}\text { between } \\
\text { group } \\
\text { (p value) }\end{array}$ \\
\hline \multirow{4}{*}{ IgG } & Placebo & $1234.8 \pm 222.7$ & $1287.0 \pm 292.0$ & 0.588 & \multirow{4}{*}{0.361} & \multirow{4}{*}{0.748} \\
\hline & Zinc & $1212.0 \pm 208.2$ & $1142.0 \pm 140.5$ & 0.310 & & \\
\hline & HIIT & $1286.0 \pm 209.6$ & $1208.0 \pm 175.7$ & 0.059 & & \\
\hline & HIIT+Zinc & $1269.0 \pm 252.3$ & $1301.1 \pm 257.9$ & 0.559 & & \\
\hline \multirow{4}{*}{ IgM } & Placebo & $136.2 \pm 34.4$ & $119.0 \pm 33.5$ & $0.003^{*}$ & \multirow{4}{*}{$0.014^{* *}$} & \multirow{4}{*}{0.066} \\
\hline & Zinc & $143.2 \pm 52.9$ & $123.6 \pm 50.3$ & $0.005^{*}$ & & \\
\hline & HIIT & $206.8 \pm 97.0$ & $213.2 \pm 116.9$ & 0.559 & & \\
\hline & HIIT+Zinc & $141.6 \pm 45.5$ & $159.8 \pm 49.5$ & 0.177 & & \\
\hline \multirow{4}{*}{ IgA } & Placebo & $175.6 \pm 72.1$ & $180.5 \pm 61.5$ & 0.747 & \multirow{4}{*}{0.649} & \multirow{4}{*}{0.264} \\
\hline & Zinc & $225.2 \pm 46.3$ & $247.2 \pm 79.9$ & 0.299 & & \\
\hline & HIIT & $202.1 \pm 31.8$ & $215.1 \pm 42.9$ & 0.325 & & \\
\hline & HIIT+Zinc & $179.7 \pm 54.4$ & $211.1 \pm 89.2$ & $0.0^{r q *}$ & & \\
\hline
\end{tabular}

Values were stated as mean \pm SD. ${ }^{*}$ Significant difference $(\mathrm{p}<0.05)$ when comparing to their Pre-test value.

${ }^{* *}$ Significant interactive change $(\mathrm{p}<0.05)$.

\section{DISCUSSION}

As previously mentioned, the combination of HIIT and futsal-specific training along with Zinc supplementation boosted the immune system through increasing IgA. 6 weeks of HIIT and futsal-specific training had no suppressing effect on the immune system of female futsal players; while, taking $30 \mathrm{mg}$ of zinc along with futsalspecific training, reduced $\operatorname{IgM}$. Finally, futsalspecific training being performed 3 sessions per week declined IgM.

Decreased IgM in the placebo group $(\mathrm{p}=0.003)$ was consistent with the findings of Xing et al. (2013), Hejazi et al. (2012), and Mashiko et al. (2004). Xing et al. (2013) and Hejazi et al. (2012) indicated that trainings before a match, i.e. during the preparation phase, had a negative impact on the immune system, whereas Asad Bakhti et al. (2012) reported that IgM and IgG levels of soccer players, before, immediately, and two hours after a bout of soccer-specific exercise had no significant difference $(11,26,31)$. Researchers suggest that increased secretion of cortisol and catecholamine hormones during exercise may cause apoptosis of the lymphocytes (32). As already known, the lymphocytes effectively produce immunoglobulins, and hence elevated cortisol and catecholamine hormones during exercise may indirectly decline the production of immunoglobulin.

Usually, there is no change in cortisol levels in light or moderate exercise. However, an ascending trend is observed in cortisol level when the intensity of activity is higher than $70 \%$ of $\mathrm{VO}_{2 \max }(32)$. Futsal as an intense sprint sport increases the level of cortisol drastically. Therefore, increased levels of cortisol in futsal training can be expected. However, cortisol levels were not measured in this study. On one hand, more than approximately $80 \%$ of a futsal match contains strenuous physical activities (33), while on the other hand, heavy physical activities have the potential to suppress the immune system (1). It should also be noted that all athletes had to participate in futsal-specific training, -three sessions per week during the six $\mathrm{o}$ their usual of only week study as compared $\mathrm{t}$ two sessions per week training. Hence, the intensity of futsal, the number of training sessions per week, and the duration of each training are the probable factors affecting the 
immune system of female futsal players (decreased $\operatorname{IgM}$ ). The innate $\operatorname{IgM}$ being produced by $\mathrm{B}_{1}$ lymphocytesdoes not need to be stimulated by antigens and causes a rapid response of the immune system to bacterial, viral, and fungal infections. Plus, adaptive IgM is produced by $\mathrm{B}_{2}$ cells $(34,35)$. A pentameric IgM has more antigen binding sites than other antibodies. Also, a single IgM molecule can activate $\mathrm{C}_{1}$ component, while several molecules are required for the same job in case of $\operatorname{IgG}(36)$.

The findings in the HIIT group demonstrated an increase in $\operatorname{IgA}$ and $\operatorname{IgM}$, and a decrease in IgG, but none of them was statistically significant. This study indicated that HIIT had no suppressing effect on the immune system and is consistent with the results of Jalili et al. (2015) and Walsh (1999). In contrast, Xiaoni et al. (2009) notified that eight weeks of HIIT weakened humoral immunity in the rowers. The contradictions are possibly rooted in the different training programs (diverse intensity, duration, volume, rest periods, and the number of training sessions per week) and also different individual characteristics (age, gender, and fitness level) (68).

Researchers alluded that exercise-induced oxidative stress can damage lymphocytic DNA, and thus reduce the number and the function of lymphocytes (producers of immunoglobulins) (32). In this study, however, HIIT did not suppress the immune function. It seems that undergoing HIIT for six weeks had some implications, which overcome the suppressing factors of the immune system in female futsal players. The mechanism of these adaptations is not yet known

In addition, in most studies, blood samples were collected just after an intense physical activity or shortly after it $(8,11)$, while in this study, they were collected two days after the last session of training. The time of blood sampling is undoubtedly very important and can cause .discrepancies in the results

In the Zinc group, a significant reduction in IgM was witnessed. Unfortunately, no research was found on the impact of zinc supplementation on humoral immunity. Most studies have examined the effect of zinc on different diseases, or have focused on the effects of zinc deficiency on the immune system. For example, Maiguma et al. (2014) reported that zinc supplementation was effective in patients with $\operatorname{IgA}$ nephropathy and prevented the aggravation of the disease. Prasad (2008) reported that zinc deficiency in men led to a reduction in serum testosterone levels, NK activity, production of IL-2, thymulin activity, etc $(20,24)$.

The results of the study by Singh et al. (1994) are not consistent with that of this research. They declared that six days of zinc supplementation (25 $\mathrm{mg}$ zinc and $1.5 \mathrm{mg}$ copper, twice a day) before exhaustive aerobic training enhanced $\mathrm{T}$ lymphocytes function, and thus strengthened the immune system (25). The contradictions may be due to a different way of supplementation (type of supplement, supplement protocol, and amount and time of consumption), or different training protocol (intensity, duration, and type of training).

As far as we know, many factors affect the immune system, such as genetics, age, gender, training, nutritional status, previous encounters with pathogens, and mental stress (10). In this study, one of the factors affecting the immune system may be mental stress The start of this study coincided with the beginning of the preparation phase before their matchesand, hence the athletes participated in futsal league s only a week after the end of this competition project. Therefore, they were probably under mental pressure for several days before their competitionsThe anxiety and mental stress in . female futsal players is normal considering the ults. According importance of the competition res

to research, almost all immunecells have receptors on their surface to connect with stress hormones, and thus are directly affected by them (37). It seems that mental stress-induced stress hormones before competitions had a negative impact on the immune system of the female futsal players. Moreover, it has been mentioned in some sources that $\operatorname{IgM}$ may interact with the innate immune cells (especially the complement) (38) in response to training-induced tissue damage, and then these $\operatorname{IgM}$ and complement complexes may be rapidly cleared from the circulation (34). As a result, IgM concentration is reduced in circulation.

Lastly, HIIT along with Zinc significantly augmented $\operatorname{IgA}$. It also increased $\operatorname{IgM}$ and $\operatorname{IgG}$, which were not significant. Unfortunately, no 
research was found based on the simultaneous effect of HIIT and Zinc supplements on the humoral immunity.

More than 300 enzymes have been identified that require zinc for their performance $(20,21)$. Zinc is a cofactor for terminal deoxynucleotidyl transferase enzyme required for the maturity, proliferation, and function of $\mathrm{T}$ cells. Moreover, thymulin (thymic hormone) needs zinc for its biological activity. This hormone is bound to high affinity receptors on $\mathrm{T}$ cells surface and ultimately improves the performance of these cells. $\mathrm{Cu}, \mathrm{Zn}$ superoxide dismutase, an important oxidative enzyme neutralizing the free radicals inside the cytoplasm, is also dependent on zinc. Totally, zinc affects the immune function due to itsdirect impact on $\mathrm{T}$ cells, as well as its antioxidant property (10, 20, 21). MHC molecules bind peptide fragments derived from the pathogens and displays them on the surface of macrophages for recognition by the proper $\mathrm{T}$ cells. Then, immature Th cells are differentiated into Th1 and Th2 cells. Th2 activation leads to the production of IL-4, IL-5, and IL-13. Next, IL4 and IL-13 stimulate B cells to produce immunoglobulin $(9,10)$. Thus, $\mathrm{T}$ cells play a crucial role in the production of immunoglobulins. As previously noted, zinc is efficient in the proliferation and function of $\mathrm{T}$ cells, and hence it indirectly affects the immunoglobulin production.

In conclusion, zinc supplementation along with HIIT strengthened the immune system by increasing IgA. IgA has two subclasses and is found in all body fluids, such as saliva, tears, milk, gastric juices, and secretions of the respiratory and genital system $(9,10,36)$. Although $\operatorname{Ig} \mathrm{A}_{1}$ is mostly found in the serum and $\operatorname{Ig} \mathrm{A}_{2}$ in the mucus, there is a positive correlation between salivary $\operatorname{IgA}$ and serum $\operatorname{Ig} \mathrm{A}$ (39). Therefore, an increase in serum $\operatorname{Ig} \mathrm{A}$ in Zinc+HIIT can indicate an increase in salivary IgA as well. Since the salivary $\operatorname{IgA}$ is the first line of defense against pathogens in the upper respiratory tract, increased salivary IgA may result in neutralization of toxins and bacteria, and protection against antigens more effectively at the beginning of the pathogens entrance, which is important (1).

\section{CONCLUSION}

To summarize, 6 weeks of HIIT had no suppressing effect on the immune system in female futsal players; even HIIT along with Zinc supplementation improved the immune system via increasing $\operatorname{IgA}$; however, 6 weeks of Zinc supplementation and also 6 weeks of futsalspecific training being performed 3 sessions per week, reduced IgM. As to the study limitations, we can refer to the sample size and uncontrolled diet of the subjects. Although during the study, participants were asked to avoid taking any other supplement but there was not any control over food intake in their diets by researcher.

It is suggested that a similar study along with controlled diet to be conducted in athletes from different sports fields. It is also suggested that elite athlete immunoglobulin levels to be investigated in the three stages of start, middle and end of the match season; as the athletes become divided into placebo and supplement group (especially antioxidants supplement).

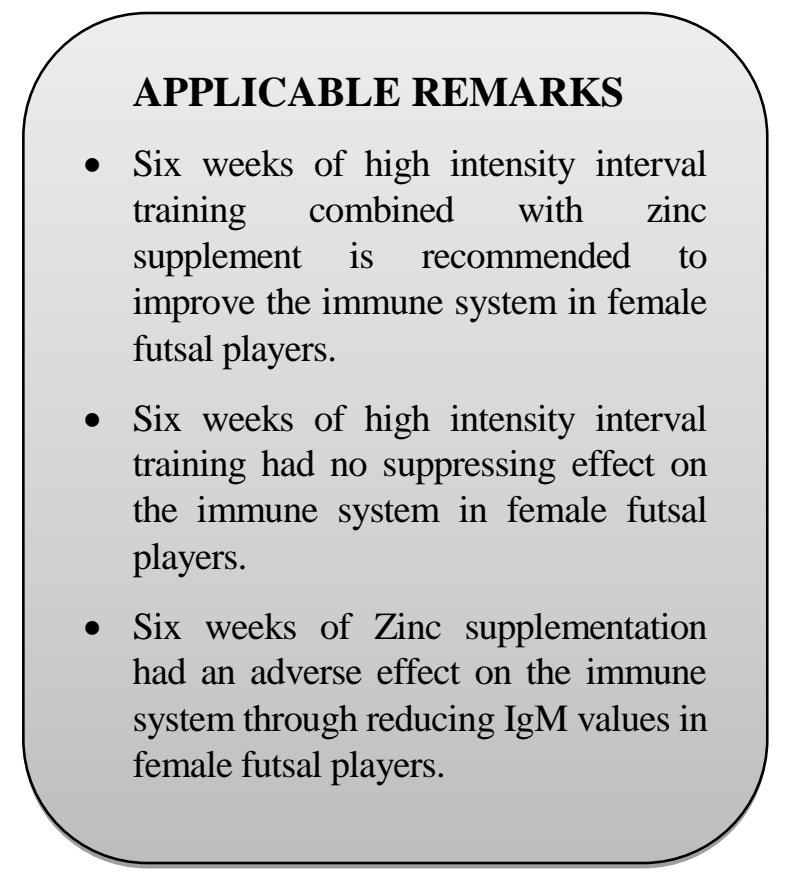

\section{ACKNOWLEDGEMENTS}

Thanks to the futsal players who gave their time to attend this study and Mrs. Maryam Reza poor, futsal coach who managed the futsal trainings as well as Gholam Rasul Mohammad Rahimi with assistance in manuscript preparation. 


\section{REFERENCES}

1. Azarbayjani MA, Nikbakht $\mathrm{H}$. The effect of continuous and intermittent training on resting level and acute response of salivary $\operatorname{IgA}$ and total protein in male basketball players. Journal of Shahrekord Uuniversity of Medical Sciences. 2010;12.

2. Owen AL, Wong DP, Dunlop G, Groussard C, Kebsi W, Dellal A, et al. High-intensity training and salivary immunoglobulin a responses in professional top-level soccer players: effect of training intensity. The Journal of Strength \& Conditioning Research. 2016;30(9):2460-9.

3. Lee N, Kim J, Am Hyung G, Park JH, Kim SJ, Kim HB, et al. Training effects on immune function in judoists. Asian journal of sports medicine. 2015;6(3).

4. Shirvani H, Ghahreman Tabrizi K, Sobhani V. Effects of high intensity intermittent exercise on serum Immunoglobulin's and Complement system response in youth soccer players. Journal of Birjand University of Medical Sciences. 2013;20(3):233-43.

5. Talebi K, Hejazi SM, Mottaghi MR, Basiry Moqadam M, Irani H, Gholami Koopaie M. Effect of intense exercise on the concentration of immunoglobulin A and salivary cortisol in swimmers. The Horizon of Medical Sciences. 2013;18(4):191-6.

6. Jalili A KH-A, Z s. The Effect of an Intense Anaerobic Exercise Session on Serum Levels of IgG, IgM and IgA in Handball, Volleyball and Climbing sports. International Journal of Medical Laboratory. 2015;2:50-7.

7. Walsh $\mathrm{N}$. The effects of high-intensity intermittent exercise on saliva $\operatorname{IgA}$, total protein and alpha-amylase. Journal of sports sciences. 1999;17(2):129-34.

8. Y X. The Research on the Influence of High Intensity Training to Rowing Athlete's IgG, IgA, IgM. Journal Jilin Institute Physical Education. 2009;3:32-7.

9. Abbas AK, Lichtman AH, Pillai S. Cellular and molecular immunology E-book: Elsevier Health Sciences; 2014.

10. Gleeson M. Immune function in sport and exercise. Journal of applied physiology. 2007;103(2):693-9.

11. A AB, S C, M.R K. The effect of a bout of soccer-specific exercise on IgA ,IgG, IgM and salivary cortisol in male soccer players. Sports physiology. 2012;15:83-96.

12. K I, E B, Wilson J ea. Harrisons Principles of Internal Medicine. New York. Mcgraw-Hill. 1994.

13. Moulds JM, Warner NB, Arnett FC. Quantitative and antigenic differences in complement component C4 between American blacks and whites. Complement and inflammation. 1991;8:281-7.

14. Bassit RA, Sawada LcA, Bacurau RF, Navarro F, Martins E, Santos RV, et al. Branched-chain amino acid supplementation and the immune response of long-distance athletes. Nutrition. 2002;18(5):376-9.

15. Mero A, Kahkonen J, Nykanen T, Parviainen T, Jokinen I, Takala T, et al. IGF-I, IgA, and IgG responses to bovine colostrum supplementation during training. Journal of Applied Physiology. 2002;93(2):732-9.

16. de Sousa MV, Madsen K, Fukui R, Santos A, da Silva MER. Carbohydrate supplementation delays DNA damage in elite runners during intensive microcycle training. European journal of applied physiology. 2012;112(2):493500 .

17. Crooks C, Cross ML, Wall C, Ali A. Effect of bovine colostrum supplementation on respiratory tract mucosal defenses in swimmers. International journal of sport nutrition and exercise metabolism. 2010;20(3):224-35.

18. Knab AM, Nieman DC, Gillitt ND, Shanely RA, Cialdella-Kam L, Henson DA, et al. Effects of a flavonoid-rich juice on inflammation, oxidative stress, and immunity in elite swimmers: a metabolomics-based approach. International journal of sport nutrition and exercise metabolism. 2013;23(2):150-60.

19. Crooks CV, Wall CR, Cross ML, Rutherfurd-Markwick KJ. The effect of bovine colostrum supplementation on salivary IgA in distance runners. International journal of sport nutrition and exercise metabolism. 2006;16(1):4764.

20. Prasad AS. Zinc in human health: effect of zinc on immune cells. Molecular medicine. 2008;14(5-6):353.

21. Prasad AS. Discovery of Human Zinc Deficiency: Its Impact on Human Health and Disease-. Advances in nutrition. 2013;4(2):176-90.

22. Micheletti A, Rossi R, Rufini S. Zinc status in athletes. Sports medicine. 2001;31(8):577-82.

23. Al-Maroof RA, Al-Sharbatti SS. Serum zinc levels in diabetic patients and effect of zinc supplementation on glycemic control of type 2 diabetics. Saudi medical journal. 2006;27(3):344-50.

24. Maiguma M, Suzuki Y, Suzuki H, Okazaki K, Aizawa M, Muto M, et al. Dietary zinc is a key environmental modifier in the progression of IgA nephropathy. PloS one. 2014;9(2):e90558.

25. Singh A, Failla ML, Deuster PA. Exercise-induced changes in immune function: effects of zinc supplementation. Journal of Applied Physiology. 1994;76(6):2298-303.

26. K H, R AH. The effect of selected exercise on serum immunoglobulin ( $\operatorname{IgA}$, IgG and $\operatorname{IgM}$ ) in middle-endurance elite runners. IJSS. 2012;2:509-14. 
27. G M. Total levels of IgM, IgA, IgG, C3, and C4 in ABO blood group. Arak Medical University Journal. 2013; 16:45-50.

28. M S, D K. The effect of high intensity interval training and moderate continuous training on aerobic and anaerobic indices in athlete men. Sports physiology. 2013;18:39-52.

29. S A, M.J HZ, Mohajeri Tehrani M.R ea. The effect of Zinc supplementation on serum lipids level and hs-CRP in diabetic individuals with over weight. IJDLD. 2011;10:614-20.

30. Gaeini A, Choobineh S, Shafiei Neek L, Satarifard S, Mahmoodzadeh M, Yar Beigi K. Effect of Zinc supplementation on serum testosterone and plasma lactate in male cyclist after one bout of exhaustive exercise. journal of shahrekord university of medical sciences. 2012;14(3).

31. Xing J-Q, Zhou Y, Fang W, Huang A-Q, Li S-B, Li S-H, et al. The effect of pre-competition training on biochemical indices and immune function of volleyball players. International journal of clinical and experimental medicine. 2013;6(8):712.

32. Tsubakihara T, Umeda T, Takahashi I, Matsuzaka M, Iwane K, Tanaka M, et al. Effects of soccer matches on neutrophil and lymphocyte functions in female university soccer players. Luminescence. 2013;28(2):129-35.

33. A.H P, R G, S A. Futsal physiology. 2nd ed:Iran. Avaye zohour. 2012.

34. Boes M. Role of natural and immune $\operatorname{IgM}$ antibodies in immune responses. Molecular immunology. 2000;37(18):1141-9.

35. Tsiantoulas D, Diehl CJ, Witztum JL, Binder CJ. B cells and humoral immunity in atherosclerosis. Circulation research. 2014;114(11):1743-56.

36. Nezlin R. The immunoglobulins: structure and function: Academic Press; 1998.

37. Glaser R, Kiecolt-Glaser JK. Stress-induced immune dysfunction: implications for health. Nature Reviews Immunology. 2005;5(3):243.

38. Nieman DC, Nehlsen-Cannarella SL. The effects of acute and chronic exercise on immunoglobulins. Sports Medicine. 1991;11(3):183-201.

39. Yamabe H, Ozawa K, Fukushi K, Ohsawa H, Chiba N, Onodera K. Elevated salivary IgA in patients with IgA nephropathy. Nephron. 1987;45(2):176-. 